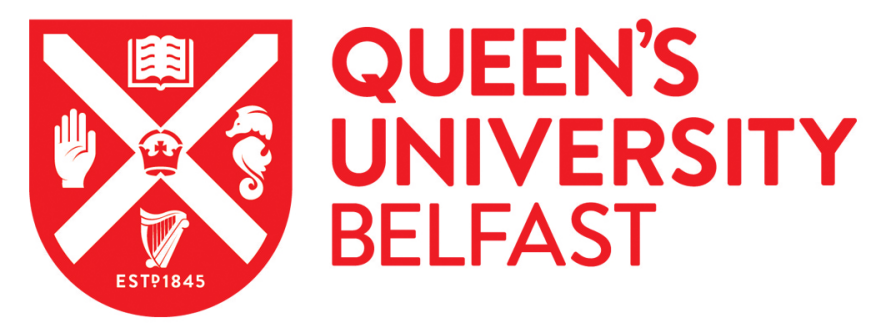

\title{
The Influence of Cation Structure on the Chemical-Physical Properties of Protic Ionic Liquids
}

Vogl, T., Goodrich, P., Jacquemin, J., Passerini, S., \& Balducci, A. (2016). The Influence of Cation Structure on the Chemical-Physical Properties of Protic lonic Liquids. The Journal of Physical Chemistry C.

https://doi.org/10.1021/acs.jpcc.6b01945

\section{Published in:}

The Journal of Physical Chemistry C

Document Version:

Peer reviewed version

Queen's University Belfast - Research Portal:

Link to publication record in Queen's University Belfast Research Portal

\section{Publisher rights}

Copyright (C) 2016 American Chemical Society

This document is the Accepted Manuscript version of a Published Work that appeared in final form in The Journal of Physical Chemistry C, copyright $\odot$ American Chemical Society after peer review and technical editing by the publisher. To access the final edited and published work see http://pubs.acs.org/doi/abs/10.1021/acs.jpcc.6b01945

\section{General rights}

Copyright for the publications made accessible via the Queen's University Belfast Research Portal is retained by the author(s) and / or other copyright owners and it is a condition of accessing these publications that users recognise and abide by the legal requirements associated with these rights.

Take down policy

The Research Portal is Queen's institutional repository that provides access to Queen's research output. Every effort has been made to ensure that content in the Research Portal does not infringe any person's rights, or applicable UK laws. If you discover content in the Research Portal that you believe breaches copyright or violates any law, please contact openaccess@qub.ac.uk. 


\section{The Influence of Cation Structure on the Chemical- Physical Properties of Protic Ionic Liquids}

Thomas Vogl ${ }^{a}$, Peter Goodrich ${ }^{b}$, Johan Jacquemin ${ }^{b}$, Stefano Passerini ${ }^{a}$ and Andrea Balducci ${ }^{a *}$

${ }^{a}$ Helmholtz Institute Ulm, Helmholtzstr. 11, 89081 Ulm, Germany

${ }^{\mathrm{b}}$ The Queen's University of Belfast, The QUILL Research Centre, Stranmillis Road, Belfast BT9 5AG, Northern Ireland (UK) 


\begin{abstract}
In this study we investigated the influence of five different cations on the physical-chemical properties of protic ionic liquids (PILs) based on bis(trifluoromethanesulfonyl)imide (TFSI'). We showed that the viscosities, ionic conductivities, densities and thermal properties of these PIL are strongly affected by the structure of the protic cation. Furthermore, the influence of the cation structure on the lithium coordination was investigated by Raman spectroscopy for all investigated PIL-based electrolytes for lithium-ion batteries (LIBs). This investigation clearly demonstrates, that the lithium average coordination number in PIL-based electrolytes is strongly affected by (ring) size and the number of protons on the cations structure and, more importantly, it might be significantly lower (more than 60\%) of that of electrolytes containing aprotic ionic liquids (AILs). Electrochemical performances of these PILs-based electrolytes were then also investigated to dress some conclusion on their applicability for LIB.
\end{abstract}




\section{INTRODUCTION}

Ionic Liquids (ILs) are nowadays considered as one of the most interesting class of chemical compounds. ${ }^{1-3}$ ILs might display high chemical and electrochemical stability, a negligible volatility and a very low flammability. Due to these properties their use as electrolytes in electrochemical storage devices, e.g. lithium-ion batteries (LIBs), has been intensively investigated in the last years. These studies indicated that ILs are very attractive electrolytes. ${ }^{4-9}$ Nevertheless, it has been shown that the performance of IL-based LIBs is limited by mainly two factors: (i) the relatively high viscosity of ILs and (ii) the relatively low mobility of the lithium ions in these types of (solvent-free) electrolytes. ${ }^{1,3,9}$ Consequently, the introduction of strategies able to improve the transport properties of IL-based electrolytes appears of extreme importance to enable their use in LIBs. Furthermore, also the cost of ILs should be carefully considered, as it is still too high for the use in commercial devices.

It is important to notice that most of the studies dedicated to the use of ILs as electrolytes for LIBs have been carried out using mainly aprotic ionic liquid (AILs). ${ }^{2-3,5-7,9-10}$ Nevertheless, we recently showed that protic ionic liquids (PILs), which are another subclass of ILs, possess all favorable properties of these chemicals and can also be successfully introduced in LIBs. ${ }^{11-14}$ Our studies indicated that there are marked differences in terms of lithium-ion coordination as well as lithium-ion environment between AIL- and PIL-based electrolytes. ${ }^{15}$ These differences have a significant impact on the behavior of LIBs, leading to a higher performance when PIL-based electrolytes are used. ${ }^{14,} 16$ Furthermore, since PILs are typically easier to synthesize and (potentially) cheaper than AILs, the use of this subclass of ILs could be also convenient in view of the commercialization of IL-based LIBs. 
Although some aspects related to the chemical-physical and electrochemical properties of PILbased electrolytes for LIBs have been already considered, a deeper understanding of the behavior of these novel electrolytes is urgently needed. Among others, an investigation of the influence of ion chemistry on the chemical-physical properties of PIL-based electrolytes appears especially

important. ${ }^{17-24}$ As a matter of fact, such information could supply valuable indication in view of the design of PILs tailored for LIB applications. ${ }^{25-28}$

In this study, we investigated the influence of five different cations on the physical-chemical properties of PILs containing the anion bis(trifluoromethanesulfonyl)imide (TFSI') as well as on the lithium coordination of PIL-based electrolytes for LIBs. Initially the ionic conductivity, viscosity, density and thermal properties (melting and decomposition temperatures) of the neat PILs have been investigated. Afterwards, the lithium coordination of the PIL-based electrolytes was studied using Raman spectroscopy. Finally, the electrochemical stability and also the performance of lithium iron phosphate (LFP) electrodes in the considered PIL-based electrolytes was investigated with particular regards to the performance at high current densities.

\section{EXPERIMENTAL SECTION}

\section{PILs Synthesis and Electrolyte Preparation}

The PILs N-butyl-pyrrolidinium bis(trifluoromethanesulfonyl)imide $\quad\left(\mathrm{Pyr}_{\mathrm{H} 4} \mathrm{TFSI}\right)$, pyrrolidinium bis(trifluoromethanesulfonyl)imide $\quad$ ( PyrнHTFSI), $_{\text {piperidinium }}$ bis(trifluoromethanesulfonyl)imide $\quad$ (PiрннTFSI), $\quad$ N-Ethylimidazolium bis(trifluoromethanesulfonyl)imide (Im/2HTFSI) and 1,1'-Carbonyl-pyrrolidin-pyrrolidinium bis(trifluoromethanesulfonyl)imide (DiPyr ${ }_{H} \mathrm{TFSI}$ ) were synthesized following a procedure similar to that described elsewhere. ${ }^{29}$ A schematic of the synthesis can be found in the supporting 
information. 1-Butylpyrrolidine (Aldrich, 98 \%), Pyrrolidine (Aldrich, 99 \%), Piperidine (Aldrich, $99 \%$ ) and 1-Ethylimidazole (Aldrich, 95\%) were distilled directly before use 1,1'Carbonyldipyrrolidine (Alfa Aesar, 98 \%), HCl (30 \%, Merck Suprapur $\left.{ }^{\circledR}\right)$ and LiTFSI (3M) were used as received. At the end of the synthesis, the obtained PILs were dried under vacuum $\left(10^{-3} \mathrm{mbar}\right)$ at $60^{\circ} \mathrm{C}$. The water content in the PIL samples was then measured using coulometric Karl-Fischer titration, and was found to be lower than $10 \mathrm{ppm}$ in each case. Samples and electrolytes were prepared in an argon-filled glove box with oxygen and water contents lower than $1 \mathrm{ppm}$. Figure 1 shows the structures of the cations contained in the PIL and the corresponding $\mathrm{TFSI}^{-}$anion investigated in this study.

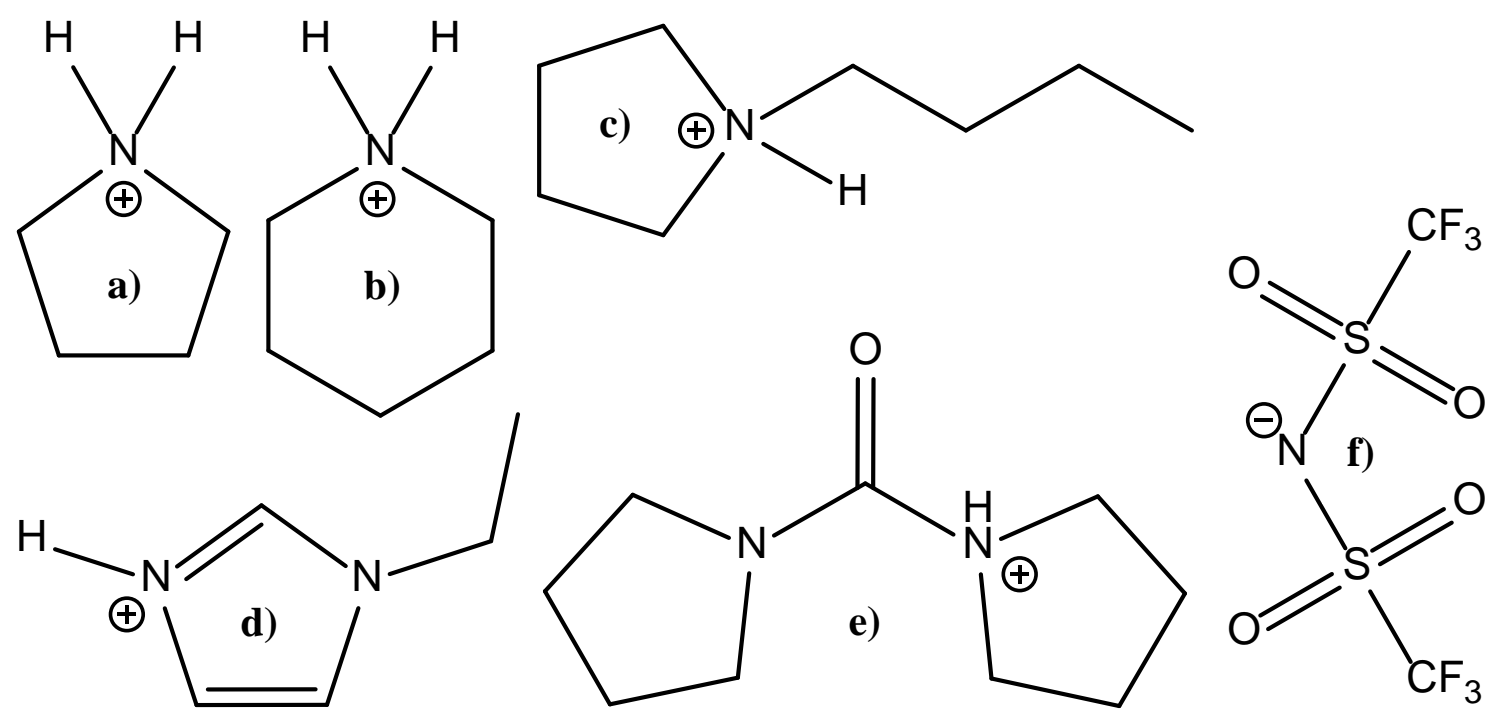

Figure 1. Cations and anion structures of the investigated protic ionic liquids: a) $\left[\mathrm{Pyr}_{\mathrm{HH}}\right]^{+}$, b) $\left[\mathrm{PipHH}^{+}\right.$, c) $\left[\mathrm{Pyr}_{4}\right]^{+}$, d) $\left[\mathrm{Im}_{\mathrm{C} 2 \mathrm{H}}\right]^{+}$, e) $\left[\mathrm{DiPyr}_{\mathrm{H}}\right]^{+}$, f) $[\mathrm{TFSI}]^{-}$.

It is mentionable, that the ${ }^{1} \mathrm{H}-\mathrm{NMR}$ of the [DiPyr $\left.\mathrm{H}\right][\mathrm{TFSI}]$ showed, that the position of the proton is not necessarily located at the nitrogen, since there is an equilibrium between two mesomeric forms. The data showed, that over $80 \%$ of the protons are located at the nitrogen and less than 
$20 \%$ located at the oxygen and thereby offering a special charge delocalization. The NMR characterization of all PILs is available in the supporting information. The NMR measurements have been carried out with a Bruker Avance (II) 200, Avance (I) 400 and Avance (III) 400. For the measurements in DMSO- $\mathrm{d}_{6}$, the rest signal of the solvent $(\delta=2.50 \mathrm{ppm}$, qu) was used as internal standard.

\section{Ionic Conductivity, Viscosity, Density and Thermal Properties of Selected PILs}

The ionic conductivity, viscosity and density of the PILs were determined as reported in reference. ${ }^{30}$ VTF parameters have been calculated using the following two equations. Equation 1 shows the VTF-equation for the inverse conductivity (resistivity, denoted $P$ ), while the equation 2 report the VTF-equation for the viscosity.

$$
\begin{array}{ll}
P=P_{0} \cdot e^{\frac{B_{c}}{T-T_{0, c}}} & \text { Equation 1 } \\
\eta=\eta_{0} \cdot e^{\frac{B_{v}}{T-T_{0, v}}} & \text { Equation 2 }
\end{array}
$$

$\left(P_{0}, B_{\mathrm{c}}, T_{0, \mathrm{c}}\right)$ and $\left(\eta_{0}, B_{\mathrm{v}}, T_{0, \mathrm{v}}\right)$ represent the type fitting parameters associated to equations 1 and 2, respectively.

Thermogravimetric analysis of the ILs was carried out using the experimental procedure reported in reference. ${ }^{14}$ Differential scanning calorimetry measurements were carried out using a Discovery DSC instrument (TA Instruments). High-temperature aluminum pans loaded with 10$20 \mathrm{mg}$ samples were used for the tests. All samples were heated to $40^{\circ} \mathrm{C}$ for equilibration, then cooled to $-150{ }^{\circ} \mathrm{C}$ and heated up to $100{ }^{\circ} \mathrm{C}$ three times with a heating rate of $5{ }^{\circ} \mathrm{C} \min ^{-1}$, using nitrogen as purge gas $\left(10 \mathrm{~cm}^{3} \mathrm{~min}^{-1}\right)$. 


\section{Raman spectroscopy}

Raman spectra of all samples were recorded and analyzed by following the same experimental technique and protocol as reported by our group previously. ${ }^{15}$

\section{Electrochemical characterization}

All the electrochemical tests were carried out with 3-electrode Swagelok ${ }^{\circledR}$ type cells. The cells were assembled in an argon-filled glove box with oxygen and water contents lower than $1 \mathrm{ppm}$. The Electrochemical stability windows (ESW) of all investigated ionic liquids have been evaluated carrying out linear sweep voltammetry (LSV) experiments in order to determine the anodic and cathodic limit of each IL separately. Fresh ionic liquids were used for the evaluation of each cathodic and anodic limit. During these experiments, the potential was scanned from OCV (which was recorded for at least 3 hours, until is was stable) toward positive and negative potentials. All measurements were carried out using a silver wire as pseudo-reference. During the time of each sweep, which was in the order of 30-45 minutes, the potential of the reference electrode was stable.

The tests were carried out at $40^{\circ} \mathrm{C}$ and the temperature was controlled by a Binder MK 53 climatic chamber. Lithium iron phosphate (LFP) composite electrodes were prepared as reported in reference. ${ }^{31}$ The composition of the dry electrodes was 85 wt.\% of the active material LFP (Südchemie), 10 wt.\% of conductive agent Super $C 65^{\circledR}\left(T I M C A L^{\circledR}\right)$ and 5 wt.\% of sodium carboxymethyl cellulose (CMC, WALOCEL ${ }^{\mathrm{TM}}$ ) as binder. The electrode mass loading was 1.5 mg $\mathrm{cm}^{-2}$; the electrode area was $1.13 \mathrm{~cm}^{2}$. LFP-based electrodes were used as working electrodes, a silver wire was used as pseudo-reference electrode (potential $\sim 3 \mathrm{~V} v s$. $\mathrm{Li} / \mathrm{Li}^{+}$) and 
an oversized activated carbon-based electrode (DLC Super $30^{\circledR}, N O R I T^{\circledR}$ ) was used as counter electrode. As separator, a Whatman GF/D glass microfiber filter (675 $\mu$ m thickness) drenched with $150 \mu \mathrm{L}$ of electrolyte was used. All the electrochemical measurements were carried out using a MACCOR Series 4000 battery tester. Constant current cycling (CC) was carried out at 40 ${ }^{\circ} \mathrm{C}$ using current densities ranging from $1 \mathrm{C}$ to $20 \mathrm{C}$ taking into account the theoretical capacity of LFP of 170 mAh $\mathrm{g}^{-1}$ when cycled between $2.8 \mathrm{~V}$ and $4.2 \mathrm{~V}$ vs. $\mathrm{Li}^{2} / \mathrm{Li}^{+}$. 


\section{RESULTS AND DISCUSSION}

\section{Ionic Conductivity, Viscosity and Density}

As mentioned in the introduction, the transport properties are particularly important in view of the use of ILs in LIBs and, more in general, in electrochemical devices. It has been widely reported that the ion size and shape and thereby charge distribution leads to different interactions between the ions. These factors are strongly influencing the ionic conductivity and viscosity of ILs. $^{20,}$ 22, 32-33 Figure 2 (a) compares the ionic conductivities of all investigated PILs in the temperature range between $30{ }^{\circ} \mathrm{C}$ to $80^{\circ} \mathrm{C}$. Even if some of the PILs had melting points below $30{ }^{\circ} \mathrm{C}$, only the properties in a region where all of the PILs were liquid are compared. For comparison, also the AIL [Pyr 14$][\mathrm{TFSI}]$ has been included in the figure. At $40{ }^{\circ} \mathrm{C}$ the PIL [ $\left.\operatorname{Im}_{\mathrm{C} 2 \mathrm{H}}\right][\mathrm{TFSI}]$ exhibits the highest ionic conductivity $\left(6.05 \mathrm{mS} \mathrm{cm}^{-1}\right)$, while the [DiPyr $\left.\mathrm{H}\right][\mathrm{TFSI}]$

has the lowest $\left(1.67 \mathrm{mS} \mathrm{cm}^{-1}\right)$. From the measurement two distinct "groups" of PILs can be identified. The first group, which displays higher ionic conductivity, includes the PILs containing the cations imidazolium and pyrrolidinium. Among them, the former shows higher ionic conductivity with respect to the latter. Specifically, the trend shown by the figure is: $\left[\mathrm{Im}_{\mathrm{C} 2 \mathrm{H}}\right]^{+}>\left[\mathrm{Pyr}_{\mathrm{HH}}\right]^{+}>\left[\mathrm{Pyr}_{4}\right]^{+}>\left[\mathrm{Pyr}_{14}\right]^{+}$. The second group, which reveals lower ionic conductivity, includes the PILs having the cation $[\mathrm{PipHH}]^{+}$or $\left[\mathrm{DiPyr}_{\mathrm{H}}\right]^{+}$. In this case, the PIL containing $\left[\mathrm{Pip}{ }_{\mathrm{HH}}\right]^{+}$shows a slightly higher ionic conductivity compared to the one with $\left[\mathrm{DiPyr}_{\mathrm{H}}\right]^{+}$. At lower temperature, the ionic conductivities of the PILs belonging to the first group are $c a .2-3 \mathrm{mS} \mathrm{cm}^{-1}$ higher than those exhibited by the second group. At higher temperature such as $80{ }^{\circ} \mathrm{C}$, this difference becomes more pronounced and a difference of more than $9 \mathrm{mS} \mathrm{cm}^{-1} \mathrm{can}$ be observed. The different ionic conductivities reported above clearly show how strong the influence of the cation size/shape is, as well as the influence of the side chain on the chemical- 
physical properties of PILs. ${ }^{22,32,34}$ In the past it has been shown that imidazolium-based ILs tend to have higher ionic conductivities compared to other types of ILs. Therefore, the high ionic conductivity of the $\left[\operatorname{Im}_{\mathrm{C} 2 \mathrm{H}}\right][\mathrm{TFSI}]$ is not surprising. ${ }^{32}$ Also the trend of decreasing ionic conductivity for increasing alkyl sidechain lengths, as observed for the pyrrolidinium-based PILs belonging to the first group, appears in line with previous findings. ${ }^{22,} 32$ Taking into account that the difference in terms of ionic conductivities between [Pipнн][TFSI] and $\left[\mathrm{Pyr}_{\mathrm{H} 4}\right][\mathrm{TFSI}]$ is much larger than that observed between $\left[\mathrm{Pyr}_{4}\right][\mathrm{TFSI}]$ and $\left[\mathrm{Pyr}_{\mathrm{HH}}\right][\mathrm{TFSI}$, it appears that ring size has a much stronger influence on the ionic conductivity than the length of the alkyl sidechain.

It is interesting to notice that when the viscosity data of the PILs are considered, a different trend with respect to the one seen for the ionic conductivities is observed. As shown inFigure 2 (b), although also in this case the two groups mentioned above are observed, the trend for the viscosity of the investigated ILs is $[\mathrm{PipHH}]^{+}>\left[\mathrm{DiPyr}_{\mathrm{H}}\right]^{+}>\left[\mathrm{Pyr}_{\mathrm{HH}}\right]^{+}=\left[\mathrm{Pyr}_{14}\right]^{+}>\left[\mathrm{Im}_{\mathrm{H}}\right]^{+}>$ $\left[\mathrm{Pyr}_{4}\right]^{+}$. At $40{ }^{\circ} \mathrm{C}$, the lowest measured viscosity is $29.23 \mathrm{mPa}$ s for the $\left[\mathrm{Pyr}_{4}\right][\mathrm{TFSI}]$, while the highest value is observed for the [Piрнн][TFSI] (99.48 mPa s). As shown, at lower temperature the two groups display markedly different viscosities (ca. $130 \mathrm{mPa}$ s between the highest and lowest measured viscosities). As expected, when the temperature increases up to $80{ }^{\circ} \mathrm{C}$ the viscosities are becoming more similar and a difference of "only" ca. $11 \mathrm{mPa} \mathrm{s}$ is observed between $[\mathrm{DiPyr} H][\mathrm{TFSI}]$ and $\left[\mathrm{Pyr}_{\mathrm{H} 4}\right][\mathrm{TFSI}]$. As stated before, not only the size of the ions matter, but also the interactions between the ions play an important role. Very likely, the trend reported above is the result of the interplay of different kinds of interactions, e.g. van der Waals interactions and H-bonds, which are taking place between the ions of the PILs. ${ }^{24}$, $34-35$ An interesting feature is observed with the pyrrolidium structure as the viscosity of the $\left[\mathrm{Pyr}_{\mathrm{HH}}\right]^{+}$is close to that observed with the $\left[\mathrm{Pyr}_{14}\right]^{+}$but both are much higher than the viscosity of the 
$\left[\mathrm{Pyr}_{4}\right]^{+}$. This observation may be associated to the cohesive energy in each IL, which tends to prove that a well-balanced van der Waals and Coulombic interactions in solution enhances the transport properties of selected ILs. Figure 2 (c) and (d) show that, for all the investigated PILs, the temperature dependence on both the resistivity and viscosity is well described by the corresponding Vogel-Tamman-Fulcher (VTF) type fitting equation. The best fitting parameters for each VTF equation are reported in Table 1, along with their correlation coefficient $\left(\mathrm{R}^{2}\right)$. The value of $T_{0}, P_{0} / \eta_{0}$ and $B$ reported in the table represent the ideal glass transition temperatures, resistivity/viscosity at infinitely high temperatures and a factor related to the fragility of the material, respectively. ${ }^{36-38}$ When comparing the ideal glass-transition temperatures derived from the ionic conductivity and viscosity measurements, it can be seen that the corresponding values for each IL show a good correlation with a deviation between these data lower than $7 \%$ in each case. Furthermore, it is also interesting to notice that the higher the $T_{0}$ of the resistivity, the lower is the measured ionic conductivity. For the $T_{0}$ values derived from the viscosity measurements, however, this trend is not that clear. As a matter of fact, the PIL with the highest measured viscosity ([Pipнн][TFSI]) has a calculated $T_{0}$ comparable to the pyrrolidinium- and imidazoliumbased PILs.

The densities of the considered ILs in the temperature range between $30^{\circ} \mathrm{C}$ and $80^{\circ} \mathrm{C}$ are shown in Figure 3. As visible, the order of the measured densities follows the trend: $\left[\mathrm{Pyr}_{\mathrm{HH}}\right]^{+}>$ $\left[\mathrm{Im}_{\mathrm{C} 2 \mathrm{H}}\right]^{+}>\left[\mathrm{PipHH}^{+}>\left[\mathrm{DiPyr}_{\mathrm{H}}\right]^{+}>\left[\mathrm{Pyr}_{\mathrm{H} 4}\right]^{+}>\left[\mathrm{Pyr}_{14}\right]^{+}\right.$. All measured densities are comprised within 1.25 and $1.60 \mathrm{~g} \mathrm{~cm}^{-3}$, which are values in line with those already reported for other IL. ${ }^{20 \text {, }}$ 39-41 

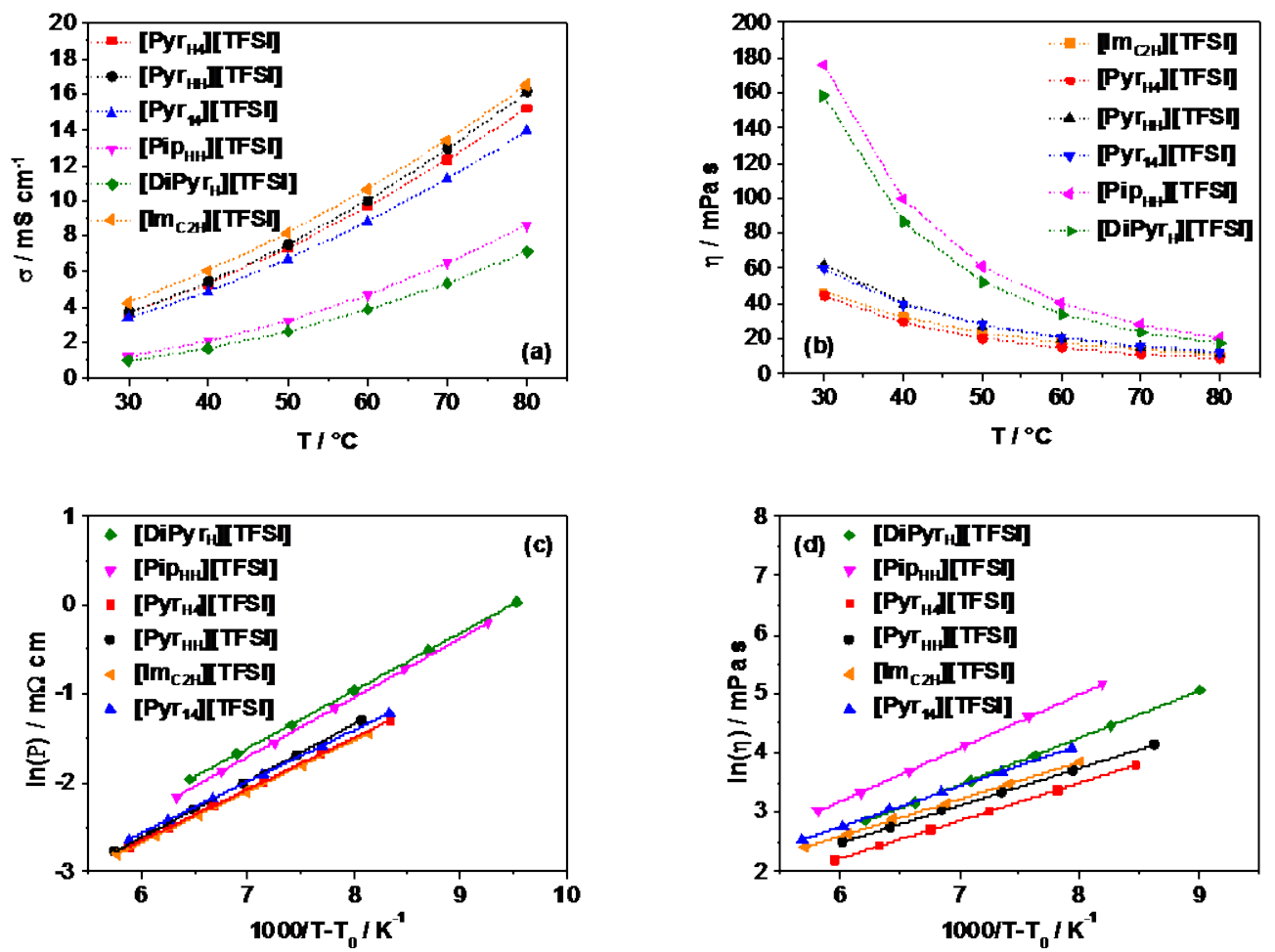

Figure 2. Ionic conductivity (a), viscosity (b) of the investigated ILs and their corresponding VTF plots (c) and (d). The solid lines represent the VTF fittings.

Table 1. VTF parameters for the resistivity and viscosity of the investigated ILs

Ionic liquid Resistivity

Viscosity

\begin{tabular}{|c|c|c|c|c|c|c|c|c|}
\hline & $\mathrm{T}_{0, \mathrm{~d}} / \mathrm{K}$ & $\mathrm{P}_{0} / \mu \Omega \mathrm{cm}^{-1}$ & $\mathrm{~B}_{\mathrm{c}} / \mathrm{K}$ & $\mathrm{R}^{2 \mathrm{a}}$ & $\mathrm{T}_{0 \mathrm{v}} / \mathrm{K}$ & $\eta_{0} / \mathrm{mPa} s$ & $\mathrm{~B}_{\mathrm{v}} / \mathrm{K}$ & $\mathrm{R}^{2 \mathrm{a}}$ \\
\hline$\left[\mathrm{DiPyr}_{\mathrm{H}}\right][\mathrm{TFSI}]$ & 198.0 & 2.059 & 653.4 & 0.9999 & 192.0 & 0.130 & 787.0 & 0.9998 \\
\hline [Рірнн][TFSI] & 195.0 & 1.708 & 666.3 & 1 & 181.0 & 0.107 & 902.7 & 0.9999 \\
\hline$\left[\mathrm{Pyr}_{4} 4\right][\mathrm{TFSI}]$ & 183.0 & 2.159 & 580.8 & 0.9999 & 185.0 & 0.200 & 637.6 & 1 \\
\hline$\left[\mathrm{Pyr}_{\mathrm{HH}}\right][\mathrm{TFSI}]$ & 179.0 & 1.582 & 638.6 & 1 & 187.0 & 0.268 & 632.5 & 0.9999 \\
\hline [Im $\left.\mathrm{Im}_{\mathrm{C} H}^{\mathrm{H}}\right][\mathrm{TFSI}]$ & 180.0 & 2.148 & 577.9 & 0.9999 & 178.0 & 0.307 & 628.3 & 0.9999 \\
\hline [Pyr $\left.{ }_{14}\right][\mathrm{TFSI}]$ & 183.0 & 2.408 & 577.6 & 0.9999 & 177.0 & 0.254 & 687.1 & 0.9999 \\
\hline
\end{tabular}




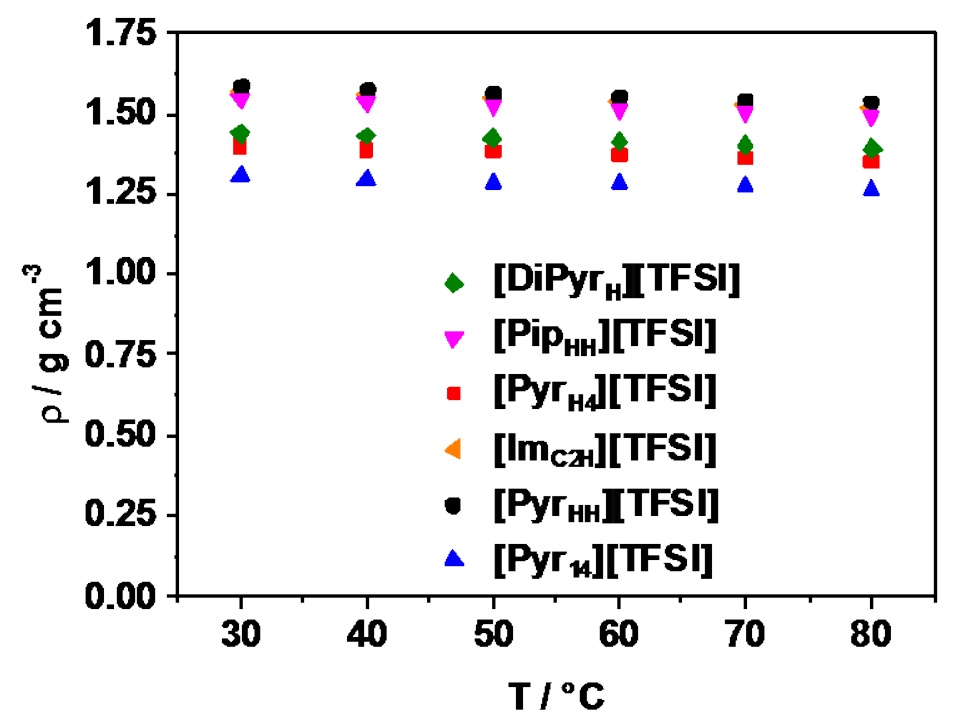

Figure 3. Density of the neat ILs in the temperature range between $30^{\circ} \mathrm{C}$ and $80^{\circ} \mathrm{C}$.

\section{Ionicity, Proton Transfer and Dissociation Degree}

In order to investigate the ionic nature of PILs more in detail, a Walden plot (Figure 4) was made. ${ }^{23,}{ }^{42}$ This plot is generally used to determine the ionicity of ionic liquids by directly relating their molar conductivity and fluidity at a given temperature. ${ }^{18}$ The values are then compared with the so-called "ideal” KCl-line, derived from a $0.01 \mathrm{M}$ aqueous $\mathrm{KCl}$ solution, where the ions are fully dissociated. ${ }^{42}$ Since PILs are generally synthetized by a neutralization reaction between a Brønsted base and a Brønsted acid, the properties of PILs are strongly dependent on the equilibrium between the ionic liquid and the corresponding educts, namely the proton transfer degree between them. This equilibrium, which is governed by the difference in $\mathrm{pK}_{\mathrm{a}}$ values of the acid and the base, determines the ionicity of the PIL. ${ }^{23,}{ }^{42-44}$ In literature, different values for a minimum $\Delta \mathrm{pKa}$ required for complete proton transfer are suggested,

ranging between $>4$ and $>10 .{ }^{17,}$ 45-46 It has been previously reported that many PILs have a lower ionicity than their corresponding AILs. This has led to many PILs being considered as 
"poor" ionic liquids. ${ }^{22}$ As shown in Table 2, the ionicity of all the considered PILs ranges between $69 \%$ and $72 \%$. These values, although they are lower than the one observed for the AIL [Pyr 14$][$ TFSI] $(81 \%)$, are higher than most of the reported or suggested for PILs in literature. ${ }^{22}$ Taking into account the results reported above, all investigated PILs could be considered as "good" ionic liquids.

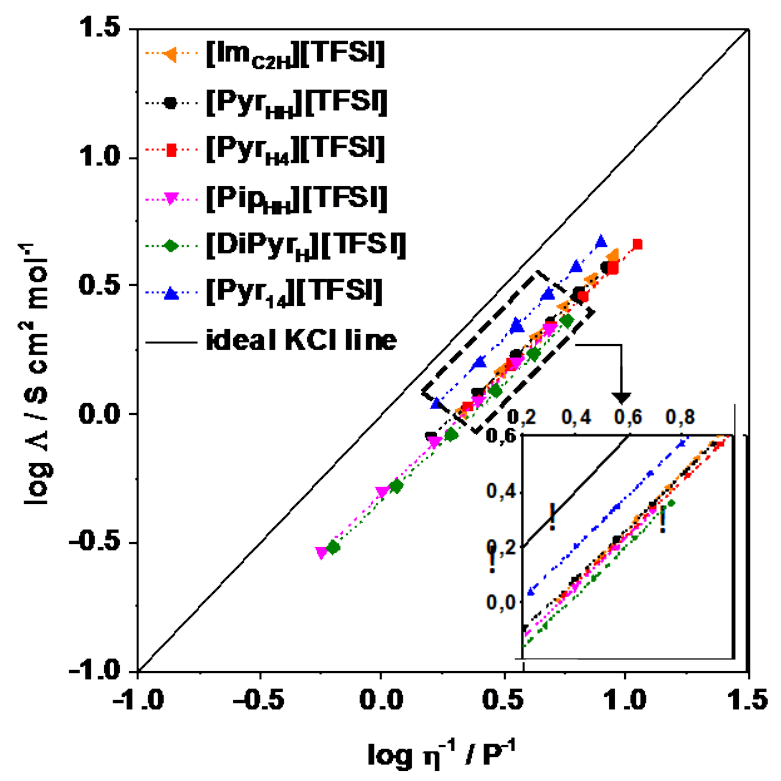

Figure 4. Walden plot of the neat ILs.

Table 2. Calculated ionicity of the ILs derived from the Walden plot.

\begin{tabular}{ll}
$I L$ & Ionicity /\% \\
\hline$\left[\mathrm{Pyr}_{14}\right][$ TFSI $]$ & 81 \\
{$\left[\mathrm{Pyr}_{44}\right][$ TFSI] } & 70 \\
{$\left[\mathrm{Pyr}_{H H}\right][$ TFSI $]$} & 72 \\
{$\left[\mathrm{Pip}_{H н}\right][\mathrm{TFSI}]$} & 72 \\
{$\left[\mathrm{Im}_{\mathrm{C} 2 \mathrm{H}}\right][\mathrm{TFSI}]$} & 72 \\
{$\left[\mathrm{DiPyr}_{\mathrm{P}}\right][\mathrm{TFSI}]$} & 69
\end{tabular}




\section{Thermal Properties}

High thermal stability is one of the key requirements for the electrolytes of LIBs. As shown in Figure 5, all PILs considered in this study display good thermal stability. [DiPyrH][TFSI], which displays the lowest thermal stability, shows a significant weight loss over $200{ }^{\circ} \mathrm{C}$. The other PILs exhibit higher thermal stability: $\left[\mathrm{Pyr}_{\mathrm{H} 4}\right][\mathrm{TFSI}]$ decomposes above $250{ }^{\circ} \mathrm{C}$, while the other PILs are stable up $300{ }^{\circ} \mathrm{C}$ and thereby are comparable with the AIL [Pyr $\left.{ }_{14}\right][\mathrm{TFSI}]$. It is also interesting to notice that a weight loss at temperature higher than the boiling points of the corresponding amines is an indication for decomposition rather than evaporation of a molecular species and thereby the full proton transfer to the cation of the PILs may be expected. This is not surprising, since the $[\mathrm{TFSI}]^{-}$anion with a $\mathrm{pK}_{\mathrm{a}}$ value of $-14^{17}$ was present in the ILs. In combination with typical $\mathrm{pK}_{\mathrm{a}}$ values of amines, all the considered PILs fulfill the before mentioned requirement of a high $\Delta \mathrm{pK}_{\mathrm{a}}$. This also supports the classification of "good" ionic liquids using the Walden plot for the investigated PILs.

In order to allow the use of an electrochemical device over a wide temperature range, the melting point also plays a significant role. It has been reported that PILs similar to AILs, can have low melting points. ${ }^{46}$ The melting temperature of each investigated PIL is presented in

Table 3. As shown in the table, [DiPyr $]$ [TFSI] did not show any sign of crystallization, but only a glass transition $\left(T_{\mathrm{g}}\right)$ observed at $-58{ }^{\circ} \mathrm{C}$. This $T_{\mathrm{g}}$ value is in good agreement with $T_{0}$ values

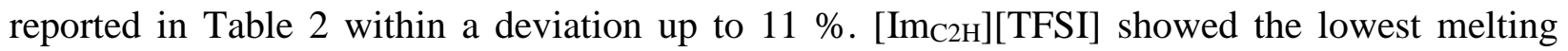
point $\left(9^{\circ} \mathrm{C}\right)$, while the pyrrolidinium- and piperidinium-based PILs have a melting point close to $37^{\circ} \mathrm{C}$ and $41^{\circ} \mathrm{C}$, respectively. The melting point displayed by these latter PILs are all higher than that of $\left[\mathrm{Pyr}_{14}\right][\mathrm{TFSI}]\left(-6{ }^{\circ} \mathrm{C}^{47}\right)$. Melting temperatures reported in Table 3 seem to follow a 
general trend, which is mainly depending on the charge localization, size and shape of the cation. In the case of the pyrrolidinium series, the degree of symmetry of groups attached on the positively charged Nitrogen atom tends to increase the melting temperature of ILs, as this process is mainly entropy driven. In fact, it is obvious to see that the order of the measured melting temperature (or $T_{\mathrm{g}}$ ) follows the trend: $\left[\mathrm{Pyr}_{\mathrm{HH}}\right]^{+}>\left[\mathrm{Pyr}_{\mathrm{H}}\right]^{+}>\left[\mathrm{Pyr}_{14}\right]^{+}>\left[\mathrm{DiPyr}_{\mathrm{H}}\right]^{+}$. Similarly, by increasing the number of Carbon atoms attached on the carbon ring from pyrrolidium to piperidium seems to increase the size and the symmetry of the cation leading thus by an increase of the melting temperature.

It is mentionable that the solidification of the considered PILs occurred several degrees below their melting temperatures (this is also the reason why some measurements were possible, even if the measured data was collected below the melting temperature of the respective IL). This is in accordance with the supercooling behavior of ILs in general. ${ }^{48-49}$

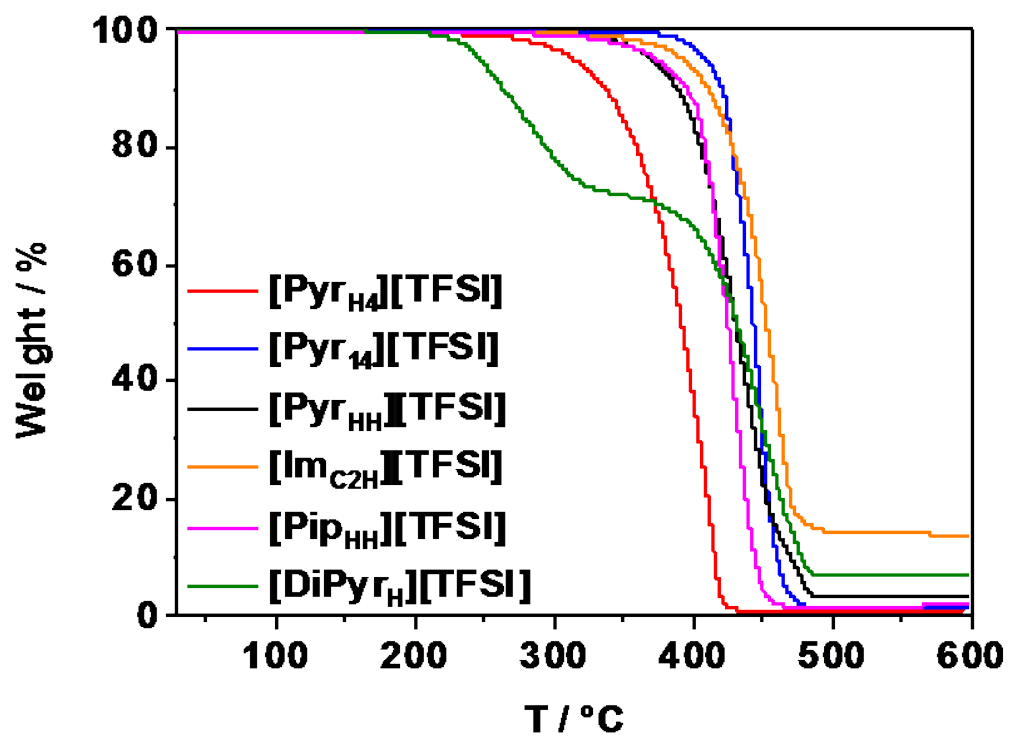

Figure 5. Thermal stability of the neat ILs. Temperature ramp: $10^{\circ} \mathrm{C} \mathrm{min}$. . 
Table 3. Melting temperatures of the neat PILs

\begin{tabular}{ll} 
PIL & $m_{p} /{ }^{\circ} \mathrm{C}$ \\
\hline$\left[\mathrm{Pyr}_{\mathrm{H} 4}\right][\mathrm{TFSI}]$ & 30 \\
{$\left[\mathrm{Pyr}_{\mathrm{HH}}\right][\mathrm{TFSI}]$} & 37 \\
{$\left[\mathrm{Pip}_{\mathrm{HH}}\right][\mathrm{TFSI}]$} & 41 \\
{$\left[\mathrm{Im}_{\mathrm{C} 2 \mathrm{H}}\right][\mathrm{TFSI}]$} & 9 \\
{$\left[\mathrm{DiPyr}_{\mathrm{H}}\right][\mathrm{TFSI}]$} & $-58^{\mathrm{a}}$ \\
{$\left[\mathrm{Pyr}_{14}\right][\mathrm{TFSI}]$} & $-6^{47}$ \\
${ }^{\mathrm{a}}$ glass transition $^{2}$
\end{tabular}

\section{Lithium-Ion Coordination}

In order to prepare electrolytic solution suitable for LIBs, the investigated ILs were mixed with the lithium salt LiTFSI. For the sake of comparison, in all the electrolytes the molar fraction of LiTFSI was fixed to 0.1. The ion-ion interactions taking place in these electrolytes have been investigated using Raman spectroscopy. As reported by several authors, in TFSI-based ILs the coordination of the anion [TFSI] $]^{-}$can be well addressed considering the peak at a wavenumber of $\sim 742 \mathrm{~cm}^{-1}$, which corresponds to the contraction/expansion of the whole TFSI- anion as well the presence of two different conformers. Upon $\mathrm{Li}^{+}$addition, this peak is partially shifted to higher wavenumbers, resulting in a shoulder of the respective peak. The analysis of this latter shoulder can be used to gain information about the number of [TFSI] ${ }^{-}$coordinated with $\mathrm{Li}^{+}{ }^{50-52}$ In a previous article, we showed that in pyrrolidinium TFSI-based PILs the cation-anion interaction is 
stronger than that in TFSI-based AILs and, as a consequence of this interaction, the number of [TFSI] ${ }^{-}$anions coordinating $\mathrm{Li}^{+}$is significantly lower in PILs with respect to AILs. ${ }^{15}$

Figure 6 displays the Raman spectra of the neat ILs investigated in this study. For comparison, the Raman spectrum of the pure $\left[\mathrm{Pyr}_{14}\right][\mathrm{TFSI}]$ is also included in the figure. As shown, in the case of [DiPyr $\left.{ }_{H}\right]\left[\right.$ TFSI] the peak relative to the [TFSI] ${ }^{-}$environment mentioned above is located at the same wavenumbers to that of the $\left[\mathrm{Pyr}_{14}\right][\mathrm{TFSI}]$, indicating that these two ILs display a comparable cation-TFSI interactions. For all the others PILs the situation is slightly different and the considered peak was shifted towards higher wavenumbers. As previously reported, such a shift indicates that the cation-anion interaction existing in these PILs is stronger compared to that of AILs. ${ }^{15}$ It is interesting to notice that the structure of the cation has an influence on the ion-ion interaction and the more protonated the cation, the stronger is its interaction with the anion. This latter point is clearly shown by the fact that the shift of $\left[\mathrm{Pyr}_{4}\right]^{+}$and $\left[\mathrm{Im}_{\mathrm{C} 2 \mathrm{H}}\right]^{+}\left(>743 \mathrm{~cm}^{-1}\right)$ is lower than that observed for $\left[\mathrm{Pyr}_{\mathrm{HH}}\right]^{+}$and $\left[\mathrm{Pip}_{\mathrm{HH}}\right]^{+}\left(>744 \mathrm{~cm}^{-1}\right)$.

Figure 7 compares the spectra of electrolytic solutions suitable for LIBs containing the investigated ILs and LiTFSI. As mentioned above, the area of the peak evolving upon $\mathrm{Li}^{+}$ addition can be used to estimate the lithium ion environment. ${ }^{30}$ As shown, the area of this peak is strongly dependent on the cation-anion interaction occurring in the IL and the stronger is this latter interaction, the lower is the area of the evolving peak. Using the spectra, we then calculated the lithium coordination number (of $\mathrm{Li}^{+}$coordinated by [TFSI]') for all ILs.

Figure 8 shows a comparison of the lithium coordination numbers of all investigated electrolytes. As shown, in the case of solution containing [Pyr 14$][\mathrm{TFSI}]$ the lithium ions are coordinated by ca. two [TFSI] ${ }^{-}$anions. This result is perfectly in line with the finding of previous works. $^{50-53}$ The average lithium coordination number of the solution containing [DiPyr $\left.{ }_{\mathrm{H}}\right]$ [TFSI] 
is in the same order of that of [ $\left.\mathrm{Pyr}_{14}\right][\mathrm{TFSI}]$, although the error associated to this measurement appears quite high. Most likely, this high error is caused by a peak related to the cation close to the peak used for the determination of the average coordination number. In all other electrolytes the average lithium coordination number appears lower than that of the $\left[\mathrm{Pyr}_{14}\right][\mathrm{TFSI}]$-based electrolyte. For example, the electrolyte containing the cation [ $\left.\operatorname{Im}_{\mathrm{C} 2 \mathrm{H}}\right][\mathrm{TFSI}]$ shows an average $\mathrm{Li}^{+}$coordination number of 1.5 [TFSI]', whereas the value decreases to 0.8 when the cation $\left[\mathrm{Pyr}_{4}\right]^{+}$is present. In the case of the electrolytes containing $\left[\mathrm{Pyr}_{H}\right]^{+}$and $\left[\mathrm{PipHH}^{+}\right.$the average coordination numbers further decrease to 0.5 and 0.4 , respectively. These results confirm that the lithium environment in PILs could be significantly different than the one of the AIL. Furthermore, these numbers also give a clear indication about the strong influence of the cation chemistry, especially with respect to the ring size and the number of protons, on the average lithium ion coordination in PIL-based electrolytes for LIBs. To the best of our knowledge, this is the first study that reports this latter and important finding in such a systematic way.

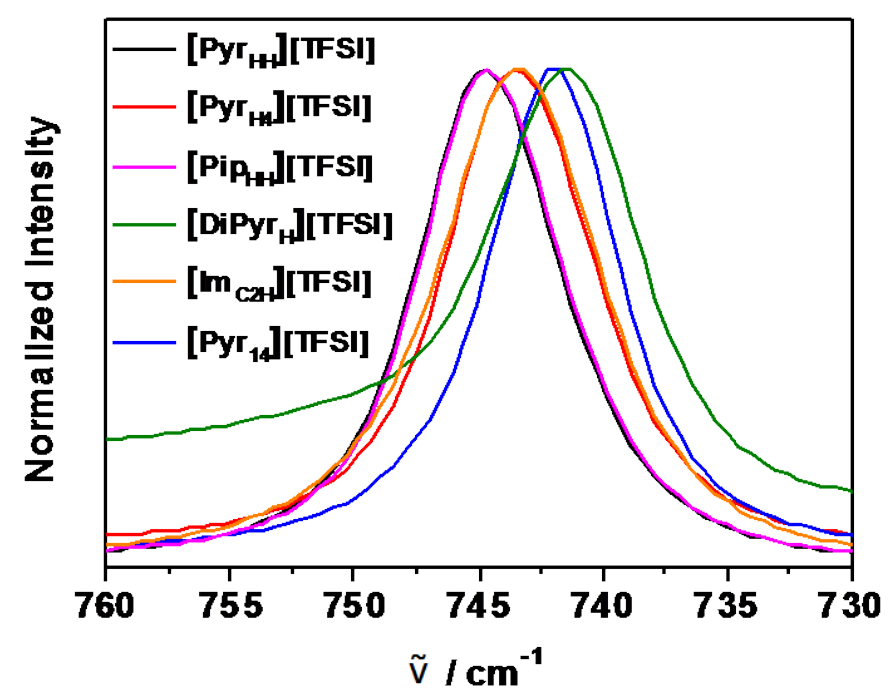

Figure 6. Raman spectra of the neat ILs in the wavenumber range between 760 and $730 \mathrm{~cm}^{-1}$. 


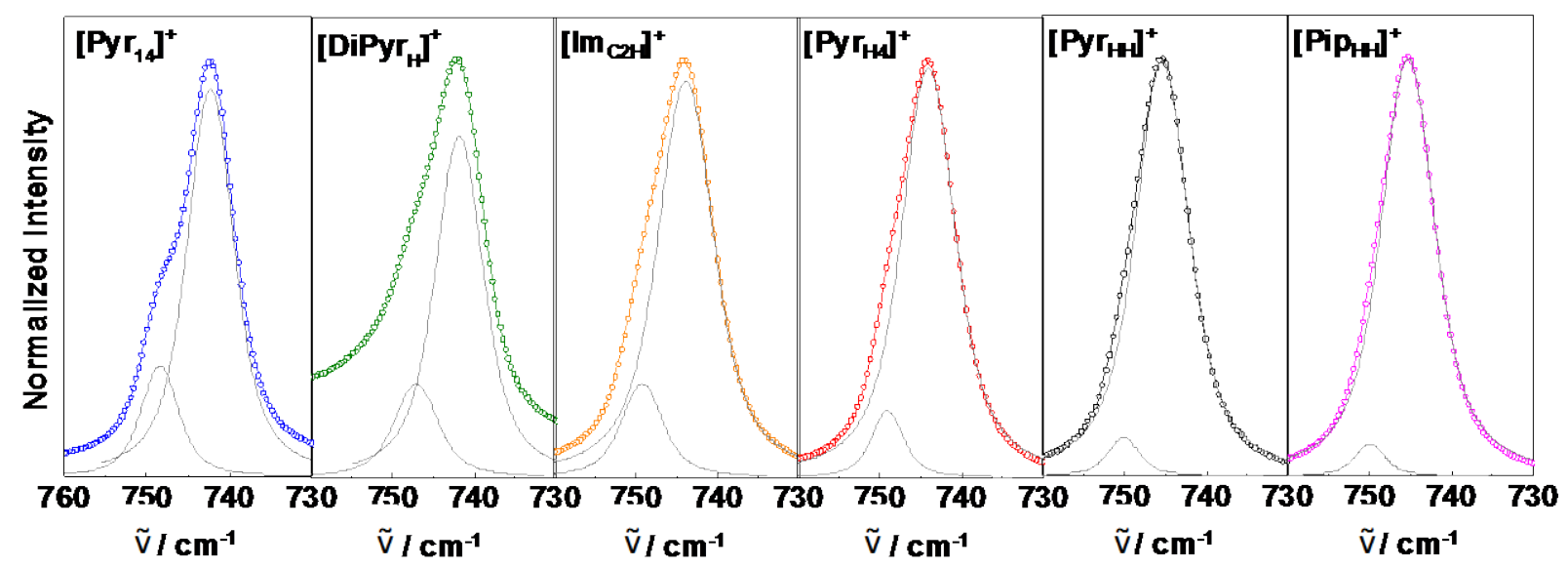

Figure 7. Raman spectra of solutions containing LiTFSI (molar fraction 0.1) and ILs in the range between 760 and $730 \mathrm{~cm}^{-1}$. The colored lines represent the measured data, the circles represent the fitted curve and the grey lines represent the two individual fitted peaks for coordinated and non-coordinated [TFSI] $]^{-}$anions.

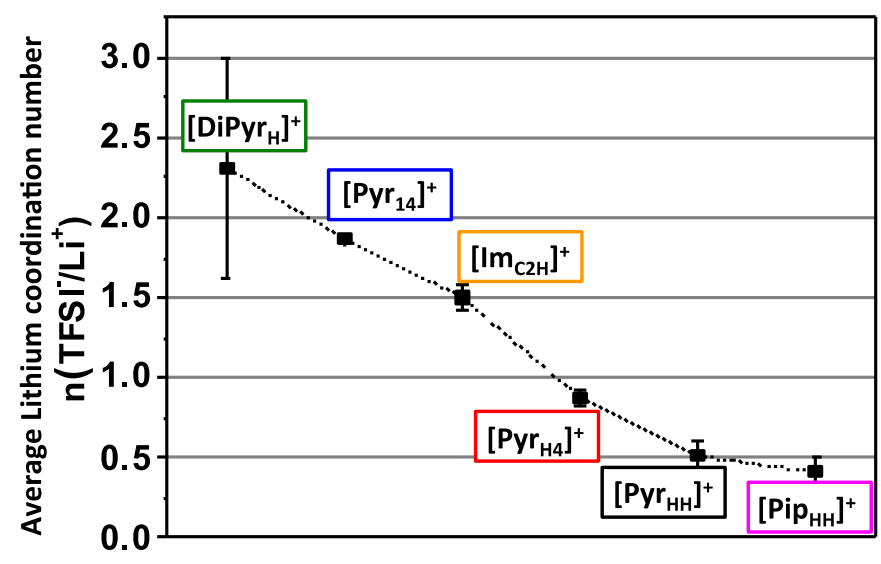

Figure 8. Average coordination numbers of $[\mathrm{TFSI}]^{-}$anions (n) coordinating $\mathrm{Li}^{+}$in the investigated electrolytes derived from the Raman intensities of the characteristic [TFSI] ${ }^{-}$band between 760 and $730 \mathrm{~cm}^{-1}$. 


\section{Electrochemical Characterization}

It is well known that the cathodic stability of PILs is determined by the deprotonation of the cation followed by the reduction of the proton, independently of the cation structure. ${ }^{29,54}$ On the other hand, the nature of the anion is mainly determining the anodic stability of PILs. ${ }^{13}$ Figure 9 compares the overall electrochemical stability windows (ESW) of electrolytic solution containing the investigated PILs and having a concentration of LiTFSI equal to $0.5 \mathrm{M}$. The measurements have been carried out using a silver quasi reference electrode and, in order to give an indication about the use of these electrolytes in LIB, the values of voltage are also reported vs. an approximated scale $\mathrm{Li} / \mathrm{Li}^{+}$. As shown, the electrolytes containing [DiPyr $\left.{ }_{\mathrm{H}}\right][\mathrm{TFSI}$ displays the lowest ESW, which is in the order of $1.2 \mathrm{~V}$. Both the cathodic and anodic stabilities of this electrolyte appear significantly lower than those of the other electrolytes and, most likely, they are both determined by the decomposition of the cation $\left[\mathrm{DiPyr}_{H}\right]^{+}$. The other electrolytes display a rather comparable anodic stability, which is determined by the anion [TFSI]- ${ }^{47,}{ }^{55}$ On the other hand, the cathodic stability limits of the electrolytes appears different and that of the electrolytes containing the cations $[\mathrm{PipHH}]^{+},\left[\mathrm{Pyr}_{\mathrm{HH}}\right]^{+}$and $\left[\mathrm{Pyr}_{\mathrm{H}}\right]^{+}$results lower than that of the electrolyte containing $\left[\mathrm{Im}_{\mathrm{H} 2}{ }^{+}\right]$(ca. $-0.8 \mathrm{~V}$ vs. Ag and $c a .-0.5 \mathrm{~V} v$ s. Ag, respectively). These latter findings are in agreement with previous works, which showed that the cathodic stability limit of PILs is much higher compared to AILs. ${ }^{13,29,54}$ 


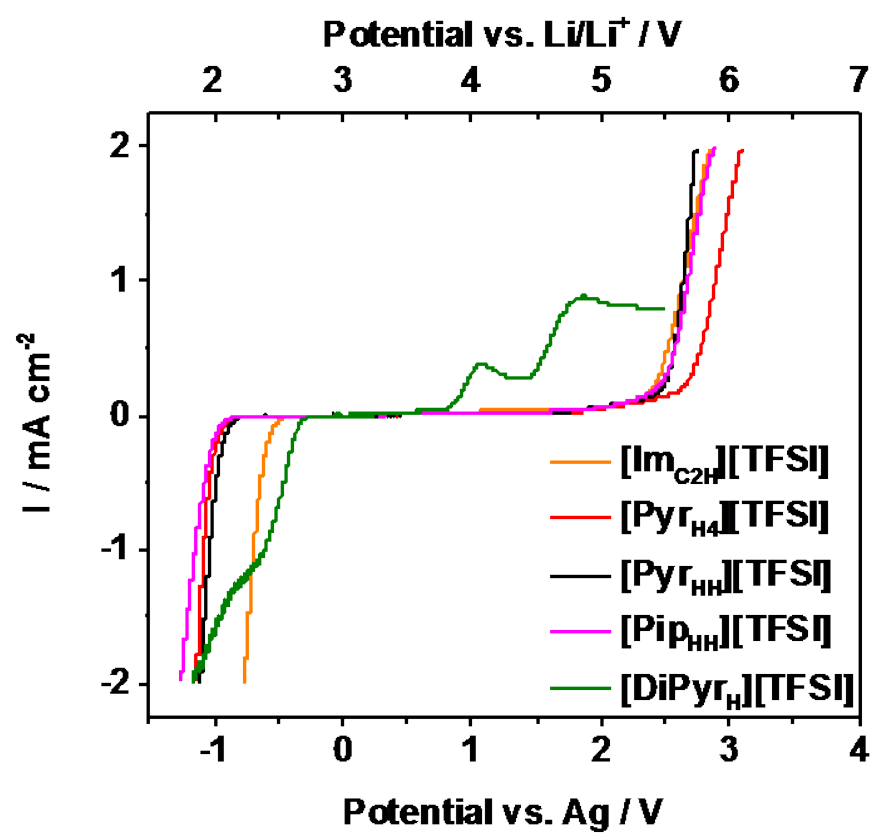

Figure 9. Electrochemical stability window of the investigated electrolytes at $40{ }^{\circ} \mathrm{C}$. In all electrolyte the concentration LiTFSI was $0.5 \mathrm{M}$. The $\mathrm{Li} / \mathrm{Li}^{+}$scale is estimated.

Taking into account the results described above, the ESW of the investigated PIL-based electrolytes appears high enough for a use in LIB containing lithium iron phosphate (LFP) as cathodic materials. ${ }^{12}$ As mentioned in the introduction, in our previous works we showed that the use of PIL-based electrolytes in LIB is especially favorable at higher current densities. For this reason, also the following investigation will focus on the use of the investigated electrolytes at elevated C-rates. ${ }^{14,}{ }^{16}$ Figure 10 compares the specific discharge capacities delivered by LFP electrodes at current densities ranging from 1C to 20C, when used in combination with the investigated PIL-based electrolytes. For comparison, the behavior of the same electrode in an electrolyte containing the "conventional" $\left[\mathrm{Pyr}_{14}\right][\mathrm{TFSI}]$ is included in the figure. Details about the voltage profiles of the positive and negative electrode of the investigated cells are given in 
the supporting information. As shown, the best performance in terms of both, specific capacity and capacity retention, was achieved using the electrolyte containing [Pyr $\left.\mathrm{H}_{4}\right][\mathrm{TFSI}]$. On the other hand, the worst overall performance was observed when [Dipyr $\left.{ }_{H}\right][\mathrm{TFSI}]$ was used. The

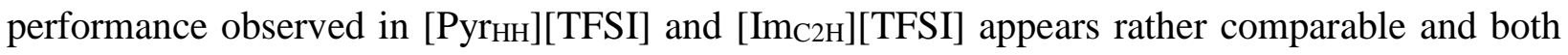
of them are superior to that observed in [Рірнн][TFSI]. The performance observed in [Pyr $\left.{ }_{14}\right][\mathrm{TFSI}]$, although higher than that of $\left[\mathrm{Pip}_{\mathrm{H}}\right][\mathrm{TFSI}]$ and [Dipyr $\left.{ }_{\mathrm{H}}\right][\mathrm{TFSI}]$, appears overall lower than observed in the other imidazolium and pyrrolidinium based PILs.

These results give important indications about the use of PIL-based electrolytes in LIBs. First of all, they confirm that the use of PIL-based electrolytes enable the implementation of systems with higher performance compared to AIL-based electrolytes. Furthermore, they give an important indication about the great influence of the chemical-physical properties of these electrolytes on the performance of battery materials. As shown in Figure 10, the specific

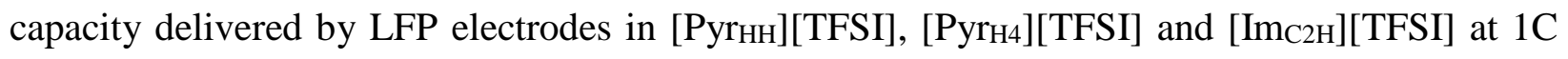
are $137 \mathrm{mAh} \mathrm{g}^{-1}, 153 \mathrm{mAh} \mathrm{g}^{-1}$ and $137 \mathrm{mAh} \mathrm{g}^{-1}$, respectively. At $40{ }^{\circ} \mathrm{C}$ [Рyrн4][TFSI] and [Im $\left.{ }_{\mathrm{C} 2 \mathrm{H}}\right][\mathrm{TFSI}]$ display comparable viscosities, while the viscosity of [Ругнн][TFSI] is higher. On the other hand the average lithium coordination numbers of [ $\left.\mathrm{Pyr}_{\mathrm{HH}}\right][\mathrm{TFSI}](0.5)$, $\left[\mathrm{Pyr}_{4}\right][\mathrm{TFSI}]$ (0.7) and $\left[\mathrm{Im}_{\mathrm{C} 2 \mathrm{H}}\right][\mathrm{TFSI}]$ (1.5) are rather different. Taking these values into account, it is reasonable to affirm that in electrolytes with comparable viscosities the performance of the LFP electrodes is mostly affected by the lithium coordination number (as for [ $\left.\mathrm{Pyr}_{\mathrm{H}}\right]$ [TFSI] and [Im $\left.\left.\operatorname{Im}_{\mathrm{C} H}\right][\mathrm{TFSI}]\right)$. In the case of electrolytes with different viscosities, the presence of a lower average lithium coordination number in the more viscous electrolyte seems to be able to compensate the unfavorable transport properties (as for $\left[\mathrm{Pyr}_{\mathrm{HH}}\right][\mathrm{TFSI}]$ and [ $\left.\mathrm{Im}_{\mathrm{C} 2 \mathrm{H}}\right][\mathrm{TFSI}]$ ). However, it is important to remark that when the viscosity of two electrolytes is considerably 
different, e.g. as for [Рipнн][TFSI] and $\left[\mathrm{Pyr}_{14}\right][\mathrm{TFSI}]$, the presence of a lower average coordination number in the more viscous electrolyte might be not sufficient to compensate the unfavorable transport properties of this latter electrolyte. This situation is well seen when the performance of the LFP electrodes in [Pipнн][TFSI] and [Pyr 14$][$ TFSI] is compared. As a matter of fact, although the coordination number of [Pipнн][TFSI] is four times lower than that of [Pyr $\left.{ }_{14}\right][T F S I]$, the performance observed in this electrolyte was not higher than those observed in the AIL, especially at medium-high C-rates. Taking into account the result reported above, the viscosity and the average lithium coordination number appears therefore as the two most important aspects influencing the performance of battery electrode and the right balance between these two parameters appears crucial for the realization of advanced PIL-based electrolytes for LIBs.

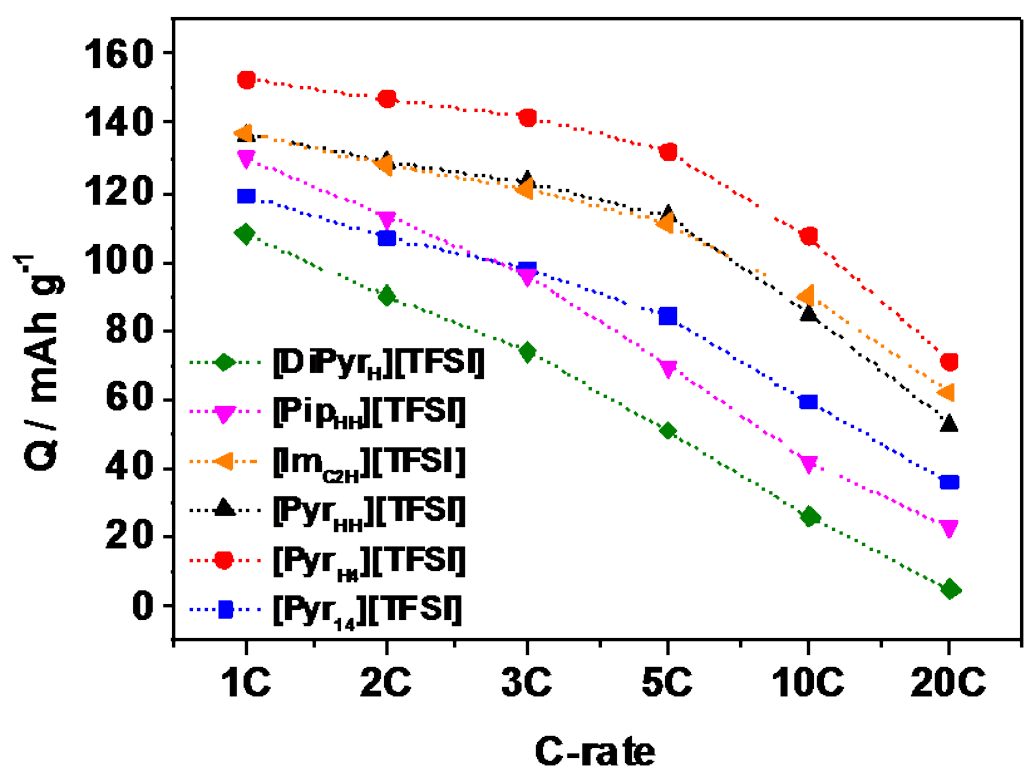

Figure 10. Rate capability of LFP electrodes in the investigated electrolytes. The tests were carried out at $40{ }^{\circ} \mathrm{C}$ using current densities ranging from $1 \mathrm{C}$ to $20 \mathrm{C}$. 


\section{CONCLUSIONS}

In this study we investigated the influence of the cation chemistry on several chemicalphysical properties of 5 different TFSI-based PILs. We showed that the viscosities and ionic conductivities of these PIL are strongly affected by the characteristic of the cation, e.g. ring size and the alkyl chain length. The results of this investigation indicated that thermal stability and also the melting points of PILs are rather comparable to that of AIL. Furthermore, we also showed that the ionicity of PILs might be close to that of AILs and, therefore, PILs can be considered as "good” ionic liquids.

The characteristic of the cation has a strong influence on the ion-ion interactions taking place in these ILs and in return, also in PIL-based electrolytes suitable for LIBs. We showed that the lithium average coordination number in PILs is strongly affected by (ring) size and the number of protons of the cations and, very important, it might be significantly lower (more than 60\%) of that of AILs. Furthermore, we confirmed that the use of PIL-based electrolytes enable the implementation of systems with higher performance compared to AIL-based electrolytes. Finally, the results of this study indicated that PILs displaying a right balanced in term of (low) viscosity and (low) average lithium coordination number should be the goal for the realization of advanced PIL-based electrolytes for LIBs. 


\section{AUTHOR INFORMATION}

\section{Corresponding Author}

*E-mail: andrea.balducci@kit.edu

\section{Author Contributions}

The manuscript was written through contributions of all authors. All authors have given approval to the final version of the manuscript.

\section{ACKNOWLEDGEMENTS}

The authors wish to thank the Bundesministerium für Bildung and Forschung (BMBF) within the project IES (contract number 03EK3010) and the Deutsche Forschungsgemeinschaft (DFG) within the project "Protic ionic liquids as electrolytes for lithium-ion batteries" for the financial support. PG and JJ wish to thanks the CEA le Ripault for its financial support through the project No 4600261677/P6E31.

\section{ASSOCIATED CONTENT}

This material is available free of charge via the Internet at http://pubs.acs.org.

NMR characterization of the protic ionic liquids, schematic procedure of the synthesis, data tables for ionic conductivity, viscosity and density, voltage profiles 


\section{REFERENCES}

(1) Etacheri, V.; Marom, R.; Elazari, R.; Salitra, G.; Aurbach, D., Challenges in the Development of Advanced Li-Ion Batteries: A Review. Energy Environ. Sci. 2011, 4, 32433262.

(2) Armand, M.; Endres, F.; MacFarlane, D. R.; Ohno, H.; Scrosati, B., Ionic-Liquid Materials for the Electrochemical Challenges of the Future. Nat. Mater. 2009, 8, 621-629.

(3) MacFarlane, D. R.; Tachikawa, N.; Forsyth, M.; Pringle, J. M.; Howlett, P. C.; Elliott, G. D.; Davis, J. H.; Watanabe, M.; Simon, P.; Angell, C. A., Energy Applications of Ionic Liquids. Energy Environ. Sci. 2014, 7, 232-250.

(4) Fernicola, A.; Scrosati, B.; Ohno, H., Potentialities of Ionic Liquids as New Electrolyte Media in Advanced Electrochemical Devices. Ionics 2006, 12, 95-102.

(5) Galinski, M.; Lewandowski, A.; Stepniak, I., Ionic Liquids as Electrolytes. Electrochim. Acta 2006, 51, 5567-5580.

(6) Lewandowski, A.; Swiderska-Mocek, A., Ionic Liquids as Electrolytes for Li-Ion Batteries: An Overview of Electrochemical Studies. J. Power Sources 2009, 194, 601-609.

(7) Wishart, J. F., Energy Applications of Ionic Liquids. Energy Environ. Sci. 2009, 2, 956961.

(8) Diallo, A.-O.; Morgan, A. B.; Len, C.; Marlair, G., An Innovative Experimental Approach Aiming to Understand and Quantify the Actual Fire Hazards of Ionic Liquids. Energy Environ. Sci. 2013, 6, 699-710.

(9) Kalhoff, J.; Eshetu, G. G.; Bresser, D.; Passerini, S., Safer Electrolytes for Lithium-Ion Batteries: State of the Art and Perspectives. ChemSusChem 2015, 8, 2154-2175.

(10) Lee, J. S.; Bae, J. Y.; Lee, H.; Quan, N. D.; Kim, H. S.; Kim, H., Ionic Liquids as Electrolytes for Li Ion Batteries. J. Ind. Eng. Chem. 2004, 10, 1086-1089.

(11) Böckenfeld, N.; Willeke, M.; Pires, J.; Anouti, M.; Balducci, A., On the Use of Lithium Iron Phosphate in Combination with Protic Ionic Liquid-Based Electrolytes. J. Electrochem. Soc. 2013, 160, A559-A563.

(12) Menne, S.; Pires, J.; Anouti, M.; Balducci, A., Protic Ionic Liquids as Electrolytes for Lithium-Ion Batteries. Electrochem. Commun. 2013, 31, 39-41.

(13) Menne, S.; Schroeder, M.; Vogl, T.; Balducci, A., Carbonaceous Anodes for Lithium-Ion Batteries in Combination with Protic Ionic Liquids-Based Electrolytes. J. Power Sources 2014, 266, 208-212.

(14) Vogl, T.; Menne, S.; Kuhnel, R.-S.; Balducci, A., The Beneficial Effect of Protic Ionic Liquids on the Lithium Environment in Electrolytes for Battery Applications. J. Mater. Chem. A 2014, 2, 8258-8265.

(15) Menne, S.; Vogl, T.; Balducci, A., Lithium Coordination in Protic Ionic Liquids. Phys. Chem. Chem. Phys. 2014, 16, 5485-5489.

(16) Vogl, T.; Menne, S.; Balducci, A., Mixtures of Protic Ionic Liquids and Propylene Carbonate as Advanced Electrolytes for Lithium-Ion Batteries. Phys. Chem. Chem. Phys. 2014, 16, 25014-25023.

(17) Angell, C. A.; Byrne, N.; Belieres, J.-P., Parallel Developments in Aprotic and Protic Ionic Liquids: Physical Chemistry and Applications. Acc. Chem. Res. 2007, 40, 1228-1236.

(18) Austen Angell, C.; Ansari, Y.; Zhao, Z., Ionic Liquids: Past, Present and Future. Faraday Discuss. 2012, 154, 9-27. 
(19) Tokuda, H.; Tsuzuki, S.; Susan, M. A. B. H.; Hayamizu, K.; Watanabe, M., How Ionic Are Room-Temperature Ionic Liquids? An Indicator of the Physicochemical Properties. J. Phys. Chem. B 2006, 110, 19593-19600.

(20) Barthen, P.; Frank, W.; Ignatiev, N., Development of Low Viscous Ionic Liquids: The Dependence of the Viscosity on the Mass of the Ions. Ionics 2015, 21, 149-159.

(21) Lane, G. H., Electrochemical Reduction Mechanisms and Stabilities of Some Cation Types Used in Ionic Liquids and Other Organic Salts. Electrochim. Acta 2012, 83, 513-528. (22) Greaves, T. L.; Weerawardena, A.; Fong, C.; Krodkiewska, I.; Drummond, C. J., Protic Ionic Liquids: Solvents with Tunable Phase Behavior and Physicochemical Properties. J. Phys. Chem. B 2006, 110, 22479-22487.

(23) Miran, M. S.; Kinoshita, H.; Yasuda, T.; Susan, M. A. B. H.; Watanabe, M., Physicochemical Properties Determined by $\Delta$ pka for Protic Ionic Liquids Based on an Organic Super-Strong Base with Various Bronsted Acids. Phys. Chem. Chem. Phys. 2012, 14, 51785186.

(24) Ueno, K.; Tokuda, H.; Watanabe, M., Ionicity in Ionic Liquids: Correlation with Ionic Structure and Physiochemical Properties. Phys. Chem. Chem. Phys. 2010, 12, 15133.

(25) Shimizu, M.; Usui, H.; Sakaguchi, H., Functional Ionic Liquids for Enhancement of LiIon Transfer: The Effect of Cation Structure on the Charge-Discharge Performance of the Li4ti5o12 Electrode. Phys. Chem. Chem. Phys. 2016, 18, 5139-5147.

(26) Garcia, B.; Lavallée, S.; Perron, G.; Michot, C.; Armand, M., Room Temperature Molten Salts as Lithium Battery Electrolyte. Electrochim. Acta 2004, 49, 4583-4588.

(27) Guerfi, A.; Duchesne, S.; Kobayashi, Y.; Vijh, A.; Zaghib, K., Lifepo4 and Graphite Electrodes with Ionic Liquids Based on Bis(Fluorosulfonyl)Imide (Fsi)- for Li-Ion Batteries. $J$. Power Sources 2008, 175, 866-873.

(28) Profatilova, I. A.; Choi, N.-S.; Roh, S. W.; Kim, S. S., Electrochemical and Thermal Properties of Graphite Electrodes with Imidazolium- and Piperidinium-Based Ionic Liquids. J. Power Sources 2009, 192, 636-643.

(29) Timperman, L.; Skowron, P.; Boisset, A.; Galiano, H.; Lemordant, D.; Frackowiak, E.; Beguin, F.; Anouti, M., Triethylammonium Bis(Tetrafluoromethylsulfonyl)Amide Protic Ionic Liquid as an Electrolyte for Electrical Double-Layer Capacitors. Phys. Chem. Chem. Phys. 2012, 14, 8199-8207.

(30) Kuehnel, R.-S.; Balducci, A., Lithium Ion Transport and Solvation in N-Butyl-NMethylpyrrolidinium Bis(Trifluoromethanesulfonyl)Imide-Propylene Carbonate Mixtures. $J$. Phys. Chem. C 2014, 118, 5742-5748.

(31) Menne, S.; Kühnel, R. S.; Balducci, A., The Influence of the Electrochemical and Thermal Stability of Mixtures of Ionic Liquid and Organic Carbonate on the Performance of High Power Lithium-Ion Batteries. Electrochim. Acta 2013, 90, 641-648.

(32) DiLeo, R. A.; Marschilok, A. C.; Takeuchi, K. J.; Takeuchi, E. S., Battery Electrolytes Based on Unsaturated Ring Ionic Liquids: Conductivity and Electrochemical Stability. J. Electrochem. Soc. 2013, 160, A1399-A1405.

(33) Tsuzuki, S.; Tokuda, H.; Hayamizu, K.; Watanabe, M., Magnitude and Directionality of Interaction in Ion Pairs of Ionic Liquids: Relationship with Ionic Conductivity. J. Phys. Chem. B 2005, 109, 16474-16481.

(34) Anouti, M.; Caillon-Caravanier, M.; Dridi, Y.; Galiano, H.; Lemordant, D., Synthesis and Characterization of New Pyrrolidinium Based Protic Ionic Liquids. Good and Superionic

Liquids. J. Phys. Chem. B 2008, 112, 13335-13343. 
(35) Anouti, M.; Porion, P.; Brigouleix, C.; Galiano, H.; Lemordant, D., Transport Properties in Two Pyrrolidinium-Based Protic Ionic Liquids as Determined by Conductivity, Viscosity and Nmr Self-Diffusion Measurements. Fluid Phase Equilibria 2010, 299, 229-237.

(36) Vogel, H., The Law of the Relation between the Viscosity of Liquids and the Temperature. Phys. Z. 1921, 22, 645-6.

(37) Fulcher, G. S., Analysis of Recent Measurements of the Viscosity of Glasses. J. Am. Ceram. Soc. 1925, 8, 339-55.

(38) Tamman, G.; Hesse, W., The Dependence of Viscosity Upon the Temperature of Supercooled Liquids. Z. Anorg. Allg. Chem. 1926, 156, 245-57.

(39) Deng, Y.; Husson, P.; Delort, A.-M.; Besse-Hoggan, P.; Sancelme, M.; Costa Gomes, M. F., Influence of an Oxygen Functionalization on the Physicochemical Properties of Ionic Liquids: Density, Viscosity, and Carbon Dioxide Solubility as a Function of Temperature. $J$. Chem. Eng. Data 2011, 56, 4194-4202.

(40) Tsunashima, K.; Sugiya, M., Physical and Electrochemical Properties of Low-Viscosity Phosphonium Ionic Liquids as Potential Electrolytes. Electrochem. Commun. 2007, 9, 23532358.

(41) Matsumoto, H.; Sakaebe, H.; Tatsumi, K., Preparation of Room Temperature Ionic Liquids Based on Aliphatic Onium Cations and Asymmetric Amide Anions and Their Electrochemical Properties as a Lithium Battery Electrolyte. J. Power Sources 2005, 146, 45-50. (42) Xu, W.; Cooper, E. I.; Angell, C. A., Ionic Liquids: Ion Mobilities, Glass Temperatures, and Fragilities. J. Phys. Chem. B 2003, 107, 6170-6178.

(43) Yoshizawa, M.; Xu, W.; Angell, C. A., Ionic Liquids by Proton Transfer: Vapor Pressure, Conductivity, and the Relevance of $\Delta$ pka from Aqueous Solutions. J. Am. Chem. Soc. 2003, 125, 15411-15419.

(44) MacFarlane, D. R.; Seddon, K. R., Ionic Liquids - Progress on the Fundamental Issues. Aust. J. Chem. 2007, 60, 3-5.

(45) Stoimenovski, J.; Izgorodina, E. I.; MacFarlane, D. R., Ionicity and Proton Transfer in Protic Ionic Liquids. Phys. Chem. Chem. Phys. 2010, 12, 10341-10347.

(46) Greaves, T. L.; Drummond, C. J., Protic Ionic Liquids: Properties and Applications. Chem. Rev. 2008, 108, 206-237.

(47) Appetecchi, G. B.; Montanino, M.; Zane, D.; Carewska, M.; Alessandrini, F.; Passerini, S., Effect of the Alkyl Group on the Synthesis and the Electrochemical Properties of N-Alkyl-NMethyl-Pyrrolidinium Bis(Trifluoromethanesulfonyl)Imide Ionic Liquids. Electrochim. Acta 2009, 54, 1325-1332.

(48) Fayer, M. D., Dynamics and Structure of Room Temperature Ionic Liquids. Chem. Phys. Lett. 2014, 616-617, 259-274.

(49) Zhou, Q.; Henderson, W. A.; Appetecchi, G. B.; Montanino, M.; Passerini, S., Physical and Electrochemical Properties of N-Alkyl-N-Methylpyrrolidinium Bis(Fluorosulfonyl)Imide Ionic Liquids: Py13fsi and Py14fsi. J. Phys. Chem. B 2008, 112, 13577-13580.

(50) Duluard, S.; Grondin, J.; Bruneel, J.-L.; Pianet, I.; Grélard, A.; Campet, G.; Delville, M.H.; Lassègues, J.-C., Lithium Solvation and Diffusion in the 1-Butyl-3-Methylimidazolium Bis(Trifluoromethanesulfonyl)Imide Ionic Liquid. J. Raman Spectrosc. 2008, 39, 627-632.

(51) Lassegues, J.-C.; Grondin, J.; Talaga, D., Lithium Solvation in

Bis(Trifluoromethanesulfonyl)Imide-Based Ionic Liquids. Phys. Chem. Chem. Phys. 2006, 8, 5629-5632. 
(52) Umebayashi, Y., et al., Raman Spectroscopic Study, Dft Calculations and Md Simulations on the Conformational Isomerism of N-Alkyl-N-Methylpyrrolidinium Bis(Trifluoromethanesulfonyl) Amide Ionic Liquids. J. Phys. Chem. B 2009, 113, 4338-4346.

(53) Lassegues, J. C.; Grondin, J.; Aupetit, C.; Johansson, P., Spectroscopic Identification of the Lithium Ion Transporting Species in Litfsi-Doped Ionic Liquids. J. Phys. Chem. A 2009, 113, 305-314.

(54) Bautista-Martinez, J. A.; Tang, L.; Belieres, J. P.; Zeller, R.; Angell, C. A.; Friesen, C., Hydrogen Redox in Protic Ionic Liquids and a Direct Measurement of Proton Thermodynamics. J. Phys. Chem. C 2009, 113, 12586-12593.

(55) Appetecchi, G. B.; Montanino, M.; Balducci, A.; Lux, S. F.; Winter, M.; Passerini, S., Lithium Insertion in Graphite from Ternary Ionic Liquid-Lithium Salt Electrolytes I.

Electrochemical Characterization of the Electrolytes. J. Power Sources 2009, 192, 599-605. 
Table of Contents Graphic

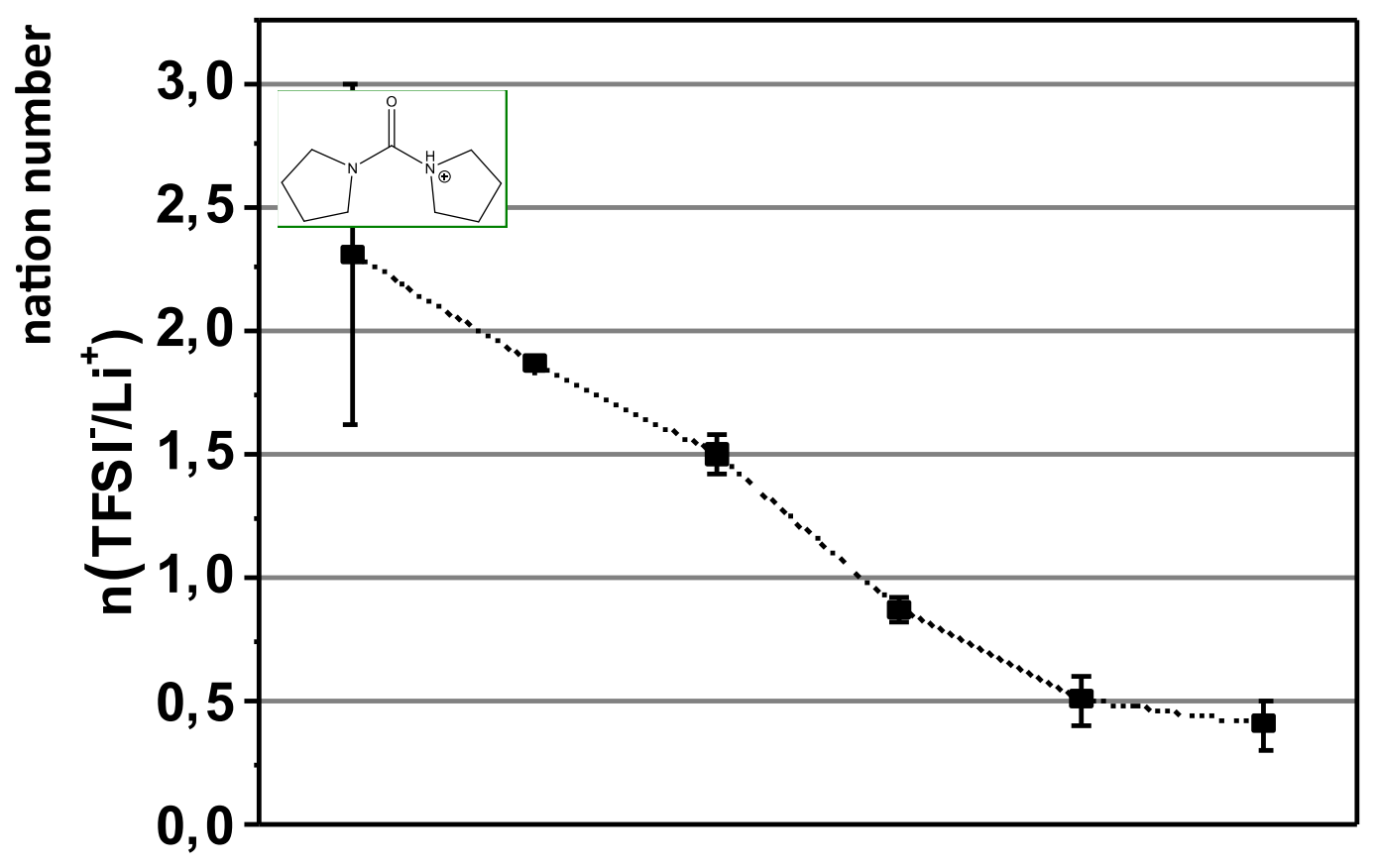

